\title{
DJ-1 degrades transthyretin and an inactive form of DJ-1 is secreted in familial amyloidotic polyneuropathy
}

\author{
SHIZUYO KOIDE-YOSHIDA ${ }^{1}$, TAKESHI NIKI ${ }^{1}$, MITSUHARU UEDA ${ }^{2}$, SHINGO HIMENO $^{2}$, \\ TAKAHIRO TAIRA ${ }^{1}$, SANAE M.M. IGUCHI-ARIGA ${ }^{3}$, YUKIO ANDO ${ }^{2}$ and HIROYOSHI ARIGA ${ }^{1}$ \\ ${ }^{1}$ Graduate School of Pharmaceutical Sciences, Hokkaido University, Sapporo 060-8589; \\ ${ }^{2}$ Department of Diagnostic Medicine, Graduate School of Medical Sciences, Kumamoto University, \\ Kumamoto 860-0811; ${ }^{3}$ Graduate School of Agriculture, Hokkaido University, Sapporo 060-8589, Japan
}

Received February 13, 2007; Accepted March 19, 2007

\begin{abstract}
DJ-1 plays roles in transcriptional regulation and anti-oxidative stress, and loss of its function is thought to result in the onset of Parkinson's disease. DJ-1 has a proteaselike structure and transthyretin (TTR), a protein causing familial amyloidotic polyneuropathy (FAP), was identified as a substrate for DJ-1 protease in this study. Both TTR and DJ-1 were secreted into the culture medium under normal conditions, and secreted TTR was not aggregated. Under oxidative conditions, TTR but not DJ-1 was secreted into the culture medium, resulting in aggregation. Mirror images of both the expression patterns and solubility of DJ-1 and TTR were observed in tissues of FAP patients, and an unoxidized form of DJ-1, an inactive form, was secreted into the serum of FAP patients. These results suggest that oxidative stress to cells abrogates secretion of DJ-1 and that secreted DJ-1 degrades aggregated TTR to protect against the onset of FAP.
\end{abstract}

\section{Introduction}

Amyloidosis is caused by the deposition of proteins that are normally soluble under physiological conditions $(1,2)$. Transthyretin (TTR) is one of the 23 human proteins known to be associated with local or systemic amyloidosis (3-6). TTR forms a homo-tetramer that carries a retinol-binding protein with retinol and thyroxine in the plasma and cerebrospinal fluid. Senile systemic amyloidosis is a sporadic disorder resulting from the deposition of wild-type TTR fibrils in cardiac and other tissues. Familial amyloidotic polyneuropathy (FAP) and cardiomyopathy are, on the other hand, hereditary autosomal-dominant diseases in which deposition of TTR fibrils is caused by amyloidogenic

Correspondence to: Dr Hiroyoshi Ariga, Graduate School of Pharmaceutical Sciences, Hokkaido University, Sapporo 060-0812, Japan

E-mail: hiro@pharm.hokudai.ac.jp

Key words: DJ-1, familial amyloidotic polyneuropathy, transthyretin mutations, and these diseases primarily affect the peripheral and autonomic nervous systems and the heart, respectively. Although it is known that TTR deposits are formed extracellularly (7), the mechanism by which FAP is caused is not clear. $D J-1$ was initially identified by us as a novel oncogene (8) and has recently been found to be a causative gene for familial Parkinson's disease PARK7 (9). DJ-1 has also been shown to be related to fertilization $(10,11)$ and tumorigenesis $(12,13)$. We and others found that DJ-1 plays roles in transcriptional regulation (14-18), mitochondrial regulation (19) and anti-oxidative stress (20-23), and loss of its function is thought to result in the onset of Parkinson's disease. In addition to its anti-oxidative stress function, DJ-1 has a structure similar to that of protease I, a cysteine protease of Pyrococcus horikoshii (24). Compared to protease I, DJ-1 contains an additional $\alpha$-helix ( $\alpha$-helix 9) at the C-terminal region, which blocks the putative catalytic site of DJ-1 and appears to regulate enzymatic activity (24). Biochemical analyses have shown that DJ-1 works as a protease (25) or chaperone $(26,27)$, though controversial results have been reported $(28,29)$. DJ-1 has three cysteines at amino acid numbers 53, 46 and 106 (C53, C46 and C106, respectively). Of the three cysteine residues, $\mathrm{C} 106$ is highly sensitive to oxidation compared to the others (32), and oxidation of C106 is essential for DJ-1 to exert its full activities, including antioxidative stress function $(22,23,33)$, protease (25) and chaperone $(26,27)$ activities. Regarding its chaperone activity, DJ-1 with $\mathrm{C} 106$ oxidized as an $\mathrm{SO}_{2} \mathrm{H}$ form, but not with $\mathrm{C} 106$ reduced or oxidized as an $\mathrm{SO}_{3} \mathrm{H}$ form, has been shown to be active (27). C53 and C46 have, on the other hand, been shown to be nitrosylated and to be necessary for dimer formation of DJ-1 (28). In addition to the oxidation of DJ-1, the activities of DJ-1 have been reported to be regulated by SUMO-1 conjugation on a lysine residue at amino acid number 130 (K130) (29).

In this study, we found that TTR co-secreted with DJ-1 into culture medium was degraded as a substrate for DJ-1 protease under normal conditions, but that secretion of DJ-1 was abrogated under oxidative conditions, resulting in the formation of amyloid fibrils of TTR. Furthermore, an inactive form of DJ-1 was secreted into the serum of FAP patients. 


\section{Materials and methods}

Cell culture and transfection. Human 293T and HEK293 cells and mouse Flp-InNIH3T3 (Invitrogen) and D2 cells (33) were cultured in Dulbecco's modified Eagle's medium with $10 \%$ calf serum. Transfection of plasmid DNAs into mouse and human cells was carried out using Lipofectamine 2000 transfection reagent (Invitrogen) according to the manufacturer's instructions and by the calcium phosphate precipitation method, respectively.

Establishment of cell lines harboring wild-type TTR or a mutant of TTR. Mutagenesis from valine to methionine at amino acid number 30 in TTR was carried out by PCR using the overlap extension method (33). An EcoRI-XhoI fragment containing Flag-tagged wild-type TTR or mutant TTR was inserted into the EcoRI-XhoI sites of pcDNA3. HEK293 cells were transfected with these DNAs and cultured in medium in the presence of $100 \mu \mathrm{g} / \mathrm{ml}$ Zeocin for 14 days. The cells resistant to the drug were then selected, and expression of Flag-DJ-1 was examined by Western blotting with an antiFlag antibody (M2, Sigma).

Detection of DJ-1 in the serum of FAP patients. Proteins in the serum of FAP patients and normal persons were subjected to immunoprecipitation with an anti-DJ-1 polyclonal antibody. The precipitates were then separated on $15 \%$ polyacrylamide gel containing SDS, transferred onto nitrocellulose membranes, and reacted with an anti-DJ-1 monoclonal antibody (3E8) or with an anti-oxidized DJ-1 antibody (34), respectively. Proteins were detected after reacting with Alexa680-conjugated anti-mouse IgG or HRP-conjugated anti-human $(\mathrm{Fab})^{2}$ antibody. The anti-oxidized DJ-1 antibody was established against a peptide containing $\mathrm{SO}_{3}$-conjugated C106 as an immunogen, and characterization of this antibody (34).

In vivo binding assay. Ten $\mu \mathrm{g}$ of pcDNA3-Flag-WT-TTR and -M30V-TTR was transfected into human 293 T cells that were $60 \%$ confluent in a $10-\mathrm{cm}$ dish by the calcium phosphate precipitation technique. Forty-eight hours after transfection, $\sim 2 \mathrm{mg}$ of proteins in the whole cell extract was first immunoprecipitated with an anti-Flag antibody (M2, Sigma) as described previously (14). The precipitates were then separated onto a $15 \%$ polyacrylamide gel containing SDS and analyzed by Western blotting with anti-DJ-1 (15) and anti-FLAG antibodies. Immunoprecipitated proteins were then reacted with IRDye800 or Alexa680-conjugated secondary antibodies and visualized by using an infrared imaging system (Odyssey, LI-COR). To see the interaction of DJ-1 with endogenously expressed TTR, the proteins were first immunoprecipitated with the anti-DJ-1 antibody and proteins in the precipitates were reacted with an anti-TTR antibody (Dako, Glostrup).

Velocity sedimentation analysis. HEK293 cell lines expressing WT-TTR and M30V-TTR were cultured up to $80 \%$ confluence in a $15-\mathrm{cm}$ dish in a serum-free OPTI-MEM medium, and protein extracts were prepared by reacting with a buffer containing $0.5 \% \mathrm{NP}-20,150 \mathrm{mM} \mathrm{KCl}, 50 \mathrm{mM}$ Tris$\mathrm{HCl}(\mathrm{pH} 7.5), 1 \mathrm{mM}$ EDTA, $2 \mu \mathrm{g} / \mathrm{ml}$ leupeptin, $2 \mu \mathrm{g} / \mathrm{ml}$ aprotinin and $2 \mu \mathrm{g} / \mathrm{ml}$ pepatatin A. Proteins in the culture medium were precipitated by $60 \%\left(\mathrm{NH}_{4}\right)_{2} \mathrm{SO}_{4}$ and dialyzed against PBS. Proteins in the cell lysates and medium were loaded onto $5-20 \%(\mathrm{w} / \mathrm{v})$ linear sucrose gradients, centrifuged for $18 \mathrm{~h}$ at $4^{\circ} \mathrm{C}$ at $35000 \mathrm{rpm}$ in an SW41 rotor, fractionated, and subjected to Western blotting with an anti-Flag or antiDJ-1 antibody.

Detection of amyloid deposition. Tissue samples were fixed with $10 \%$ formalin, embedded in paraffin, serially sectioned at a thickness of $3 \mathrm{~mm}$, and placed onto microscope slides. Sections were stained with hematoxylin and alkaline Congo red and were examined under polarized light in the presence of green birefringence $(35,36)$.

Staining procedures. Slides were treated with $0.3 \% \mathrm{H}_{2} \mathrm{O}_{2}$ in PBS for 30 min to block endogenous peroxidase activity and incubated in a blocking buffer containing $0.5 \%$ bovine serum albumin and 5\% goat serum in PBS for $1 \mathrm{~h}$ at room temperature in a moist chamber. Slides were reacted with a rabbit antihuman TTR antibody (Dako, Glostrup) diluted (1:100) in PBS, incubated at $4^{\circ} \mathrm{C}$ overnight, and washed with PBS. After the slides had reacted with a horseradish peroxidaseconjugated goat anti-rabbit IgG antibody (Dako) diluted $1: 100$ in the blocking buffer, the reactivity of the proteins was visualized with a DAB liquid system (Dako). Sections were also counterstained with hematoxylin. For parallel control sections, a primary antibody was replaced by the blocking buffer $(35,36)$.

Sandwich ELISA immunoassay procedure. DJ-1 secreted into the serum of FAP patients (V30M) was measured by using Human DJ-1 ELISA kit (CycLex's, Japan).

Protease activity of DJ-1. A peptide library, FRETS-25Xaa, was obtained from Peptide Institute and used according to the supplier's manual. FRETS-25Xaa is composed of DA2pr(Nma)-Gly-Zaa-Yaa-Xaa-Ala-Phe-pro-Lys(Dnp)-DArg-A-Arg, in which Xaa has 19 amino acids lacking cysteine; Yaa is a mixture of Lys, Asp, Tyr, Ile and Pro; and Zaa is a mixture of Arg, Glu, Phe, Val and Ala. After $10^{-4} \mathrm{M}$ of each amino acid of FRETS-25Xaa was incubated with various amounts of GST-free DJ-1 in a buffer containing $0.5 \mathrm{mM}$ sodium acetate $(\mathrm{pH} 5.5)$ and $0.2 \mathrm{mM} \mathrm{CaCl}_{2}$ at $37^{\circ} \mathrm{C}$ for $60 \mathrm{~min}$, the highest fluorescence of amino acid of $\mathrm{X}$ was determined by measurement of its fluorescence $(E x=360 \mathrm{~nm}$, $\mathrm{Em}=465 \mathrm{~nm}$ ) using a fluorescent altimeter.

\section{Results}

TTR as a substrate for DJ-1 protease. GST-tagged DJ-1 was expressed in and purified from E. coli, and GST was cleaved off by digestion of GST-DJ-1 by ProScission ${ }^{\text {TM }}$ protease (GE Healthcare). To examine the protease activity of DJ-1, recombinant full-sized DJ-1 was reacted with peptide mixtures of FRETS-25Xaa, and the intensity of fluorescence produced by the degradation of the peptides was measured (Fig. 1). The purity of recombinant DJ-1 was $>99 \%$ as described previously (15). DJ-1 was found to possess protease activity in the presence of 0.1-10 $\mathrm{mM} \mathrm{Ca}^{2+}$ (Fig. 1A). 
A

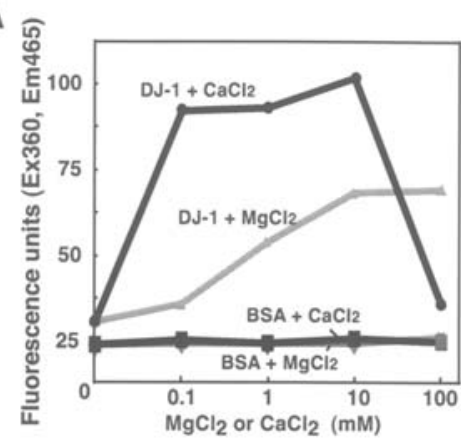

B

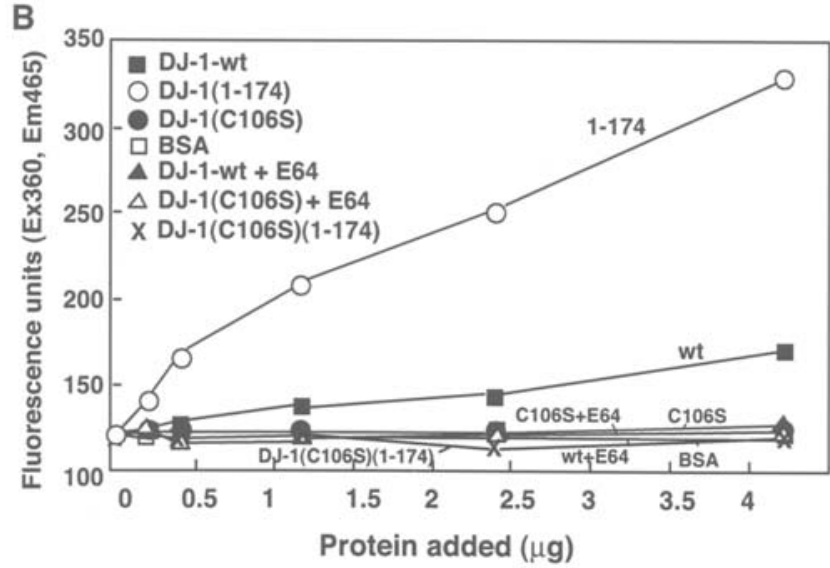

Figure 1. Protease activity of DJ-1. GST-DJ-1 and GST-mutants of DJ-1 were expressed in and purified from E. coli as described previously. Purified GST-free DJ-1 and -mutants of DJ-1 were then obtained after digesting GST-DJ-1 and GST-mutants of DJ-1 with PreScission protease to cleave-off GST. (A) Peptide mixtures $\left(10^{-4} \mathrm{M}\right)$ of FRETS-25Xaa consisting of Gly(Arg/Glu/Phe/Val/Ala)-(Lys/Asp/Tyr/Ile/Pro)-Arg-Ala-Phe-lys-Arg-Arg were reacted with $1 \mu \mathrm{g}$ of DJ-1 at $37^{\circ} \mathrm{C}$ for $60 \mathrm{~min}$ in a buffer containing various concentrations of $\mathrm{CaCl}_{2}$, and their fluorescences $(\mathrm{Ex}=360 \mathrm{~nm}$, $\mathrm{Em}=465 \mathrm{~nm}$ ) were measured using a fluorescent altimeter. (B) Peptide mixtures $\left(10^{-4} \mathrm{M}\right)$ of FRETS-25Xaa were reacted with various amounts of DJ-1 and mutants of DJ-1 at $37^{\circ} \mathrm{C}$ for $60 \mathrm{~min}$ in a mixture as described in Material and methods, and their fluorescences $(E x=360 \mathrm{~nm}, E m=465 \mathrm{~nm})$ were measured using a fluorescent altimeter.
Protease activity of DJ-1 was also found to be active at $\sim$ pH 5.5 (data not shown). Full-sized DJ-1 showed weak protease activity, and a C106S mutant of DJ-1, a mutant with a substitution of cysteine to serine at amino acid number 106 corresponding to a catalytic amino acid of protease activity $(24,25)$, had no protease activity (Fig. 1B). DJ-1 (1-174), a truncated form of DJ-1 spanning amino acids 1-174 and lacking $\alpha$-helix 9 , however, showed strong protease activity, and protease activities of both full-sized DJ-1 and DJ-1 (C1174) were completely lost in the presence of E64, an inhibitor for cysteine protease (Fig. 1B), suggesting that the C-terminal region hindered protease activity of DJ-1 in vitro.

To identify the substrate protein for DJ-1 protease, expression levels of proteins in a DJ-1-knockdown cell line, D2, and its parental mouse NIH3T3 cells (Flp-In-3T3) were compared by two-dimensional gel electrophoresis, and proteins were stained by SYPRO Ruby (Fig. 2). The expression levels of 3 proteins designated by arrows were markedly increased. These protein spots were then broached, digested with trypsin and identified by mass spectrometry (Table I). Three identified proteins were cellular retinoic-acid-binding protein chain A, transthyretin (TTR) and immunoglobulin light chain, and the expression level of TTR was markedly increased. To examine TTR as a target protein for DJ-1 protease, D2 and NIH3T3 cells were transfected with Flagtagged TTR (F-TTR) and an increased expression level of FTTR in D2 cells was found by Western blot analysis (Fig. 3A), confirming the results of the proteome analysis. When D2 cells were cotransfected with full-sized wild-type DJ-1 or C106S mutant DJ-1 together with F-TTR, the expression level of TTR was decreased by wild-type DJ-1 but not by C106S mutant DJ-1 (Fig. 3B). Furthermore, wild-type TTR (WT-TTR) and a substitution mutant of TTR (V30M) purified from human tissues were degraded in a dosedependent manner by recombinant wild-type DJ-1 (1-174) but not by C106S mutant DJ-1 (1-174) in vitro (Figs. 3C and D), indicating that TTR is a substrate for DJ-1 protease. The results also suggest that $\alpha$-helix 9 in DJ-1 is opened or
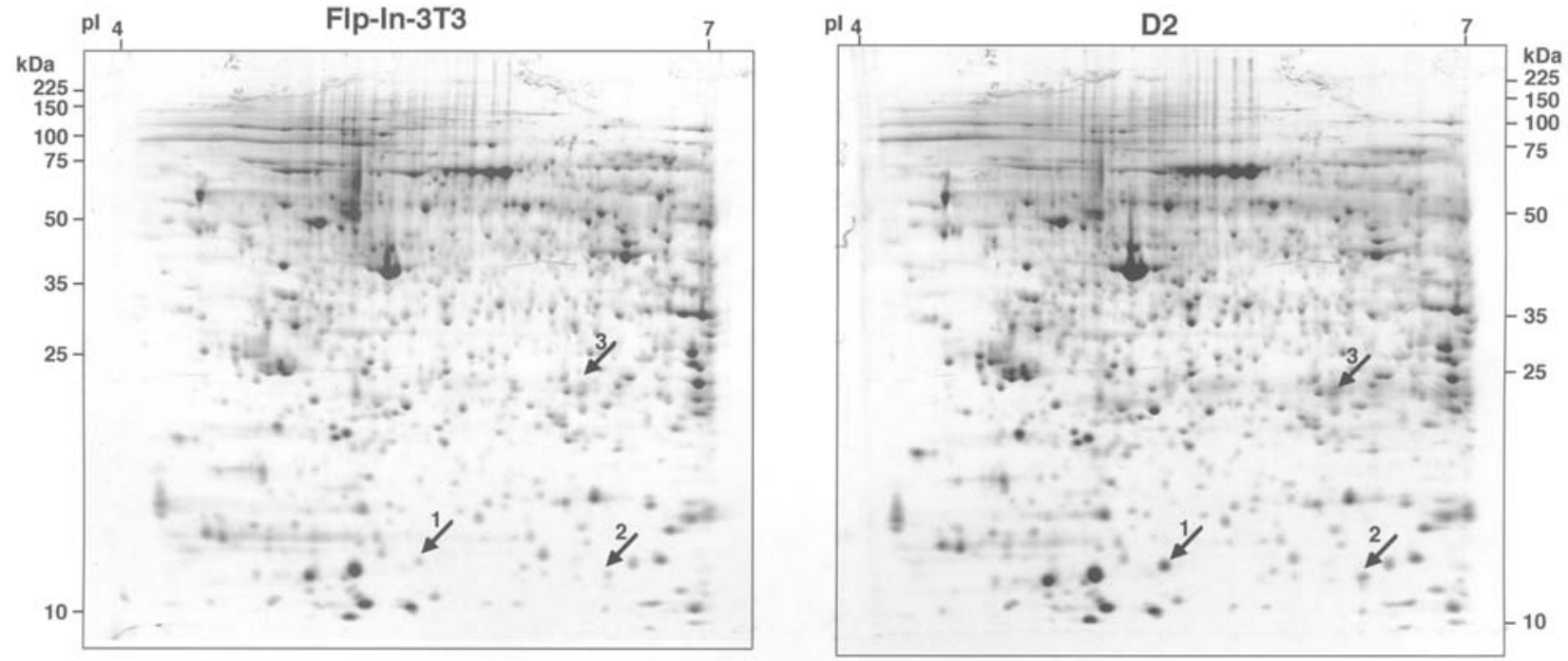

Figure 2. Comparison of proteins whose expression levels were changed in NIH3T3 and DJ-1-knockdown cells. Proteins were extracted from NIH3T3 (FlpIn-3T3) and its DJ-1-knockdown D2 cells, separated on a two-dimensional gel electrophoresis gel and stained with SYPRO Ruby. Arrows indicate proteins whose expression levels were changed in NIH3T3 and DJ-1-knockdown cells. 
Table I. Identification of proteins whose expression levels were changed in D2 cells by TOF-MS analysis.

\begin{tabular}{lccl}
\hline Spot no. & \multicolumn{2}{c}{ Experimental } & \multicolumn{1}{c}{ Identified protein } \\
\cline { 2 - 3 } & $\mathrm{pI}$ & $\mathrm{MW}(\mathrm{kDa})$ & chain A, cellular retinoic-acid-binding protein \\
\hline 1 & 5.5 & 15 & transthyretin precursor \\
2 & 6.0 & 15 & immunoglobulin light chain \\
\hline
\end{tabular}

A

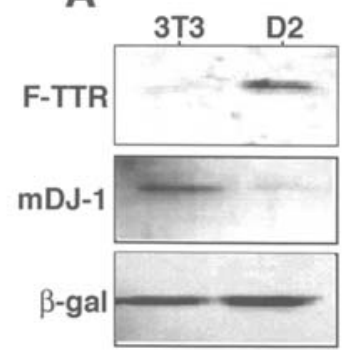

B

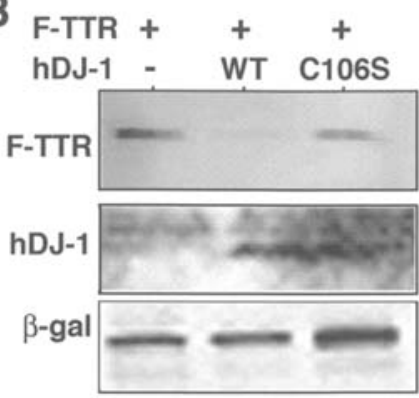

\section{C. in vitro WT-TTR}
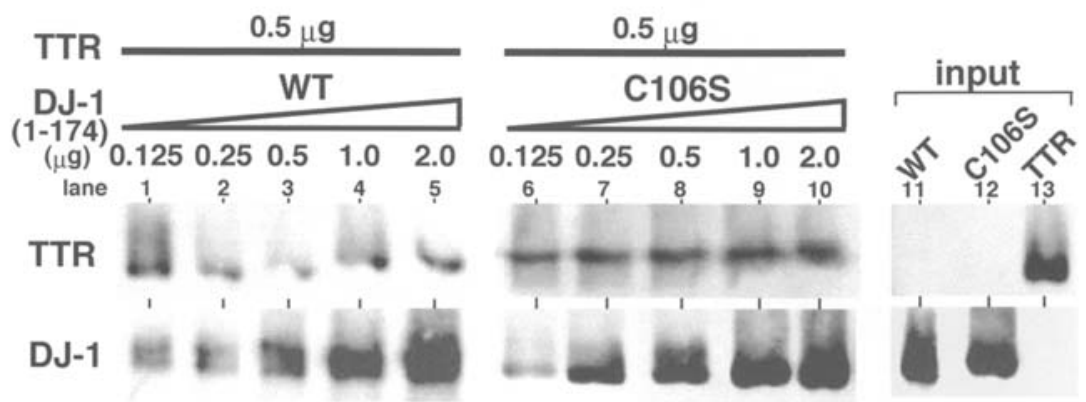

\section{D. in vitro V30M-TTR}
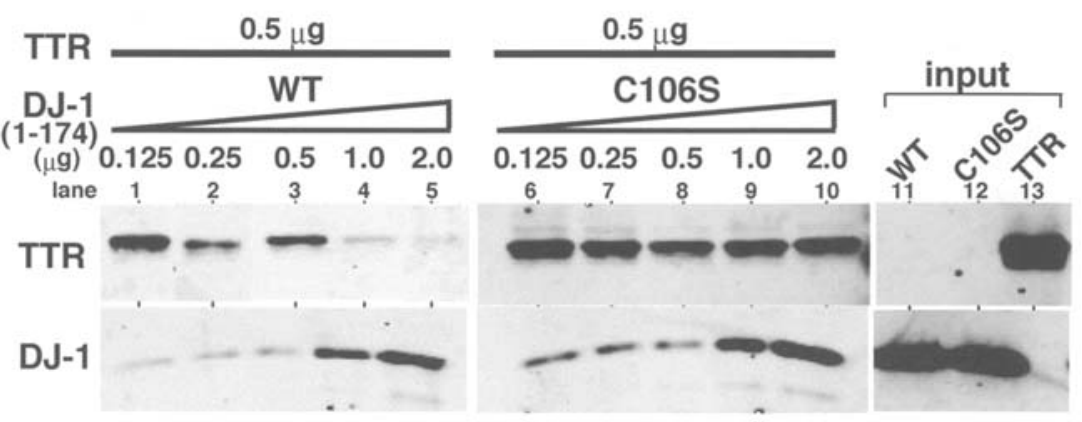

Figure 3. Degradation of TTR by DJ-1. (A) NIH3T3 and D2 cells were transfected with expression vectors for Flag-tagged TTR and B-galactosidase. Fortyeight hours after transfection, proteins in transfected cells were analyzed by Western blotting with anti-Flag, anti-mouse DJ-1 and anti- 3 -galactosidase antibodies as described in Materials and methods. (B) D2 cells were transfected with expression vectors for Flag-tagged full-sized wild-type DJ-1 or C106S mutant DJ-1 together with TTR and B-galactosidase, and the expression levels of these proteins were analyzed by Western blotting. (C, D) Wild-type (WT) (C) and mutant TTR proteins (V30M) (D) purified from human tissues were incubated in vitro with truncated forms of wild-type and C106S DJ-1 [DJ-1 (1174)] in a buffer containing $0.5 \mathrm{mM}$ sodium acetate $(\mathrm{pH} 5.5)$ and $0.2 \mathrm{mM} \mathrm{CaCl}_{2}$ for $4 \mathrm{~h}$ at $37^{\circ} \mathrm{C}$. The proteins in the mixtures were analyzed by Western blotting with anti-DJ-1 and anti-TTR antibodies.

cleaved by DJ-1-binding protein(s) in cells, into which fullsized DJ-1 was transfected, to exert protease activity.

To examine the association of DJ-1 with TTR in cells, 293T cells were transfected with Flag-WT-TTR and -M30VTTR, proteins from transfected cells were immuno- precipitated with an anti-Flag antibody or nonspecific IgG, and the precipitates were analyzed by Western blotting with an anti-DJ-1 antibody (Fig. 4A). The results showed that both Flag-WT-TTR and -V30M-TTR were co-immunoprecipitated with DJ-1 (Fig. 4A, upper part). To examine the 
A

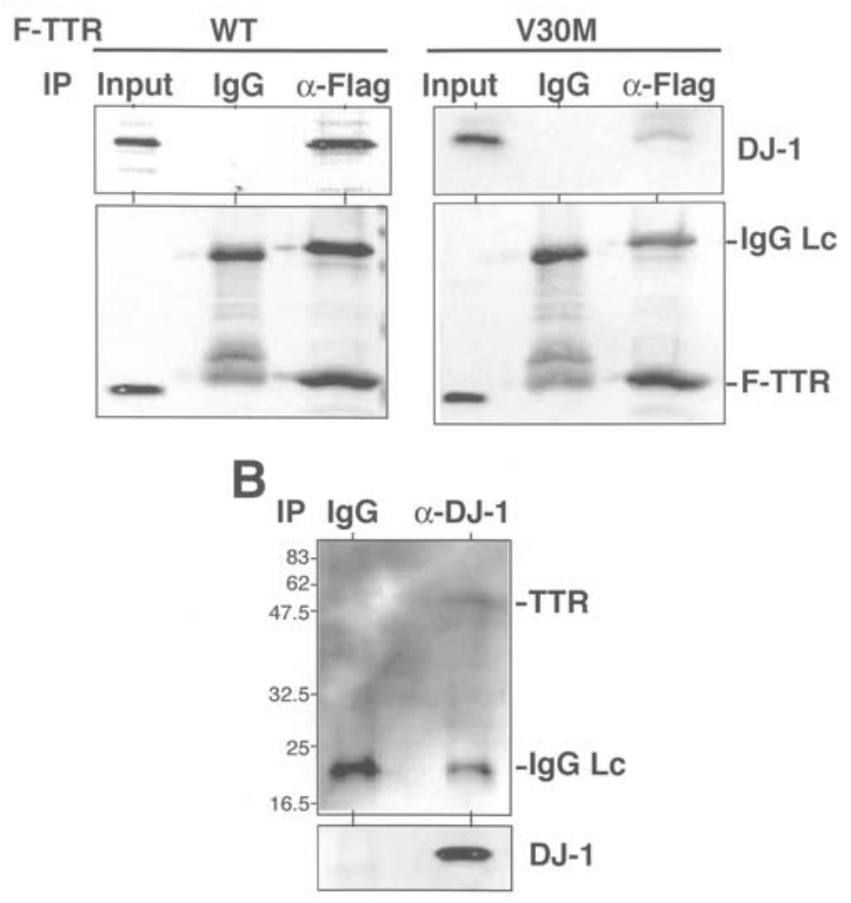

Figure 4. Association of DJ-1 with TTR. (A) 293 T cells were transfected with an expression vector for Flag-WT-TTR or Flag-V30M-TTR. Fortyeight hours after transfection, proteins in whole cell extracts were immunoprecipitated with an anti-Flag antibody or non-specific $\mathrm{IgG}$, and the immunoprecipitates were then analyzed by Western blotting with an antiFlag or anti-DJ-1 antibody. (B) Proteins extracted from 293T cells were first immunoprecipitated with an anti-DJ-1 antibody or non-specific $\mathrm{IgG}$, and the precipitates were then analyzed by Western blotting with an anti-TTR or anti-DJ-1 antibody.

interaction of DJ-1 with TTR at the endogenous level, proteins from human $293 \mathrm{~T}$ cells were immunoprecipitated with the anti-DJ-1 antibody, and the precipitates were then analyzed by Western blotting with an anti-TTR antibody (Fig. 4B). The results showed that DJ-1 was associated with a tetramer of WT-TTR in $293 \mathrm{~T}$ cells.

Co-secretion of DJ-1 with TTR. Since TTR secreted from cells forms an amyloid in FAP and the onset of FAP is thought to be related to oxidative stress (37), the distribution of DJ-1 and the conformation of TTR in cells and culture medium were examined. To do this, 293T cells expressing Flag-WT-TTR or Flag-V30M-TTR were established. These cells were treated with $5 \mu \mathrm{M} \mathrm{H}_{2} \mathrm{O}_{2}$ for $20 \mathrm{~h}$ or not treated. Proteins extracted from cells with an NP-40-containing buffer and proteins in the culture medium were then separated through a $5-20 \%$ sucrose density gradient, and proteins in each fraction were analyzed by Western blotting with antiFlag and anti-DJ-1 antibodies (Fig. 5). Without treatment of $\mathrm{H}_{2} \mathrm{O}_{2}$, while DJ-1 in the cells was co-distributed over the range of molecular mass $150 \mathrm{kDa}$ with monomer and dimer forms of both WT-TTR and V30M-TTR, DJ-1 in the culture medium was co-distributed with a tetramer but not a monomer of WT-TTR and V30M-TTR. With treatment of $\mathrm{H}_{2} \mathrm{O}_{2}$, DJ-1 in the cells was co-distributed with a monomer of WT-TTR and monomer and dimer forms of V30M-TTR. Furthermore, while no DJ-1 in the culture medium was observed, increased amounts of monomer, dimer and tetramer forms of both WT-TTR and V30M-TTR were observed, indicating that DJ-1 was co-secreted into the culture medium with tetramer TTR under normal conditions and that secretion of DJ-1 was abrogated and the level of monomer TTR which triggers amyloid formation in the medium was increased after oxidative stress.

Secretion of an inactive form of DJ-1 in the serum of FAP patients. To examine the characteristics of DJ-1 and TTR, proteins from the hearts of FAP patients containing TTR amyloid were separated into $1 \%$ Triton X-100-soluble and -insoluble fractions and analyzed by Western blotting (Fig. 6A). The majority of TTR and DJ-1 was found to be present in insoluble and soluble fractions, respectively. Localization of TTR and DJ-1 in FAP patients was further examined by an immunohistochemical analysis using hearts and lumbar nerves of FAP patients (Fig. 6B). Congo red staining in the heart sections showed apple-green birefringence characteristic of congophilic amyloid deposits around the interstice of myocardial cells in all the specimens (Fig. 6B$\mathrm{CR}$ ), which was confirmed by emission of an emerald-green birefringence in polarized light (Fig. 6B-PL). While all of the amyloid deposits were immunoreactive with an anti-TTR antibody, they were not immunoreactive with an anti-DJ-1 antibody (Fig. 6, TTR and DJ-1). These results indicate that localizations of TTR and DJ-1 in myocardial cells were in a mirror image; TTR was localized in the amyloid and DJ-1 was localized around the amyloid. Results similar to or the same as those in the heart were obtained in the lumbar nerve (Fig. 6B, right part).

Since DJ-1 and TTR have been shown to be secreted into the serum of breast cancer patients (12) and FAP patients (6), respectively, the amounts of DJ-1 in the serum of normal persons, FAP (V30M) patients and V30M-containing carriers were measured by a sandwich ELISA (Fig. 6C). The DJ-1 level in the serum was significantly $(\mathrm{p}=0.006)$ higher in FAP (V30M) patients than in normal persons and TTR-V30Mcarrier patients, indicating that more DJ-1 was secreted into the serum in FAP patients than in healthy and V30Mcontaining carriers. Since the oxidative state of DJ-1 determines its biological activity and oxidation of C106 is essential for DJ-1 to exert its full activities, including antioxidative stress function $(22,23,33)$, protease $(25)$ and chaperone $(26,27)$ activities, DJ-1 in the serum of FAP (V30M) patients, V30M-containing carriers and healthy persons was analyzed by Western blotting with anti-DJ-1 and anti-oxidized DJ-1 antibodies (Fig. 6D). The anti-oxidized DJ-1 antibody recognizes only oxidized DJ-1 at C106 (34). The results showed that DJ-1 in the serum of FAP patients was unoxidized DJ-1, which may be an inactive form of DJ-1, and that DJ-1 in healthy persons and V30M-containing carriers was oxidized.

\section{Discussion}

Structural analysis of DJ-1 has shown that DJ-1 has a structure similar to that of protease I, a cysteine protease of Pyrococcus horikoshii (24), and Olzmann et al have reported that DJ-1 has protease activity using casein as a substrate 
A. WT-TTR

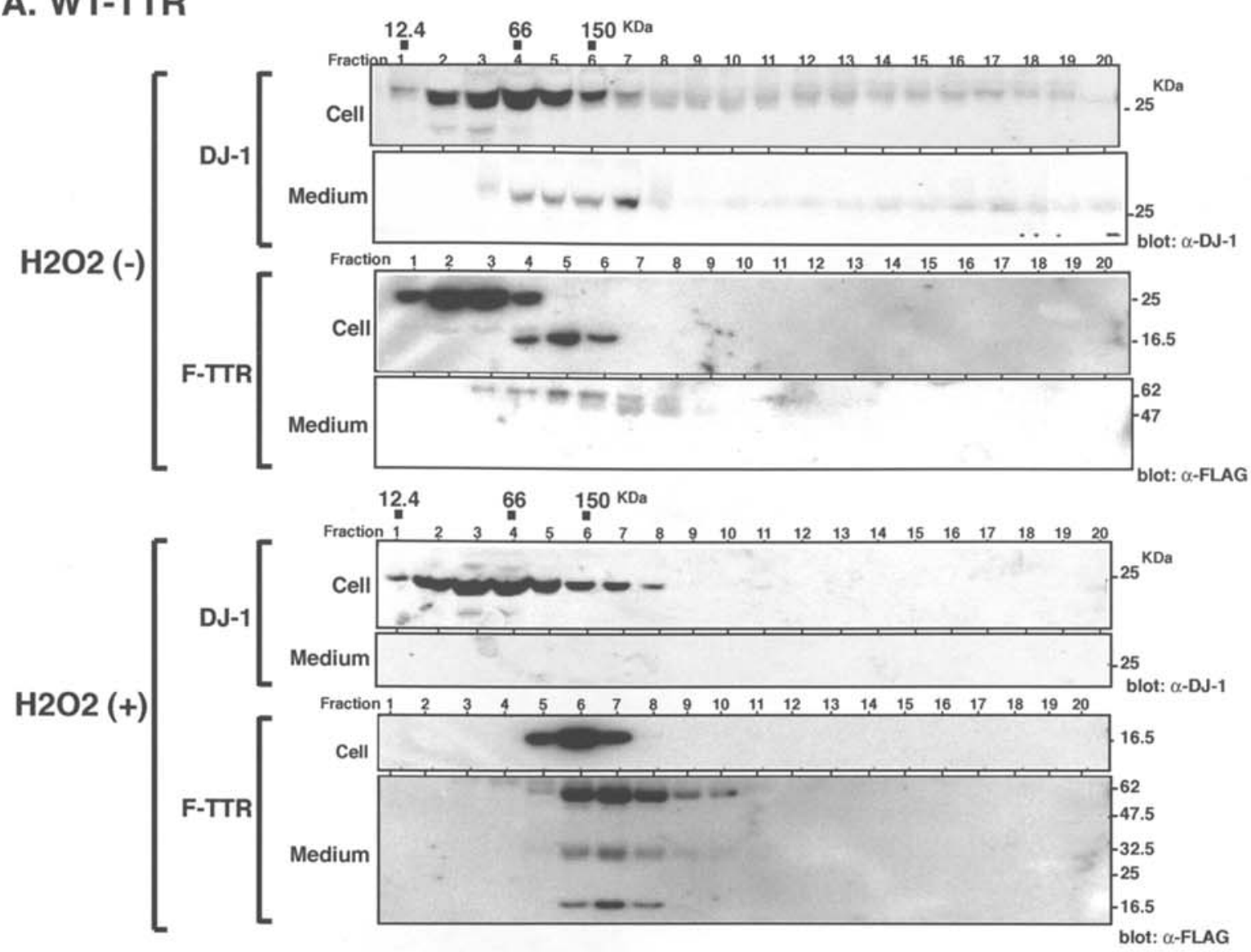

B. V30M-TTR
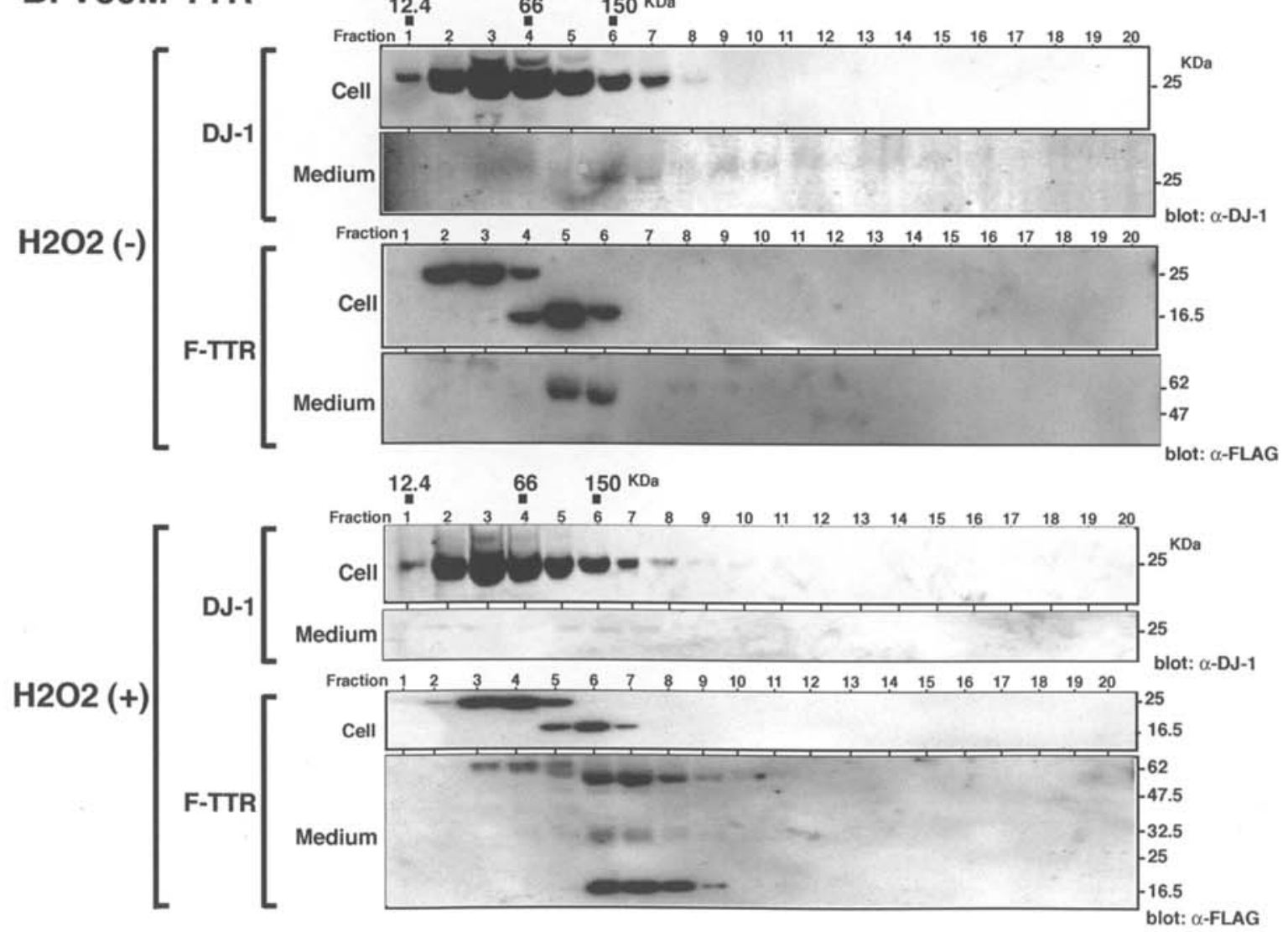

Figure 5. Co-secretion of DJ-1 with TTR and abrogation of DJ-1 secretion by oxidative stress. 293(WT-TTR) (A) and 293(V30M) (B) cells were treated with or without $5 \mu \mathrm{M} \mathrm{H}_{2} \mathrm{O}_{2}$ for $20 \mathrm{~h}$, and proteins extracted from cells with an NP-40-containing buffer and proteins in the culture medium were then separated through a 5-20\% sucrose density gradient. Proteins in each fraction were analyzed by Western blotting with anti-Flag and anti-DJ-1 antibodies. 


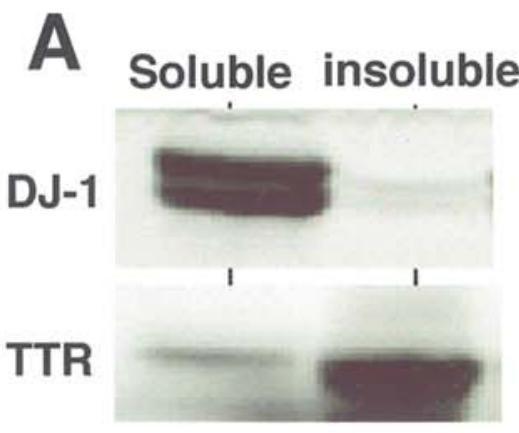

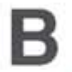
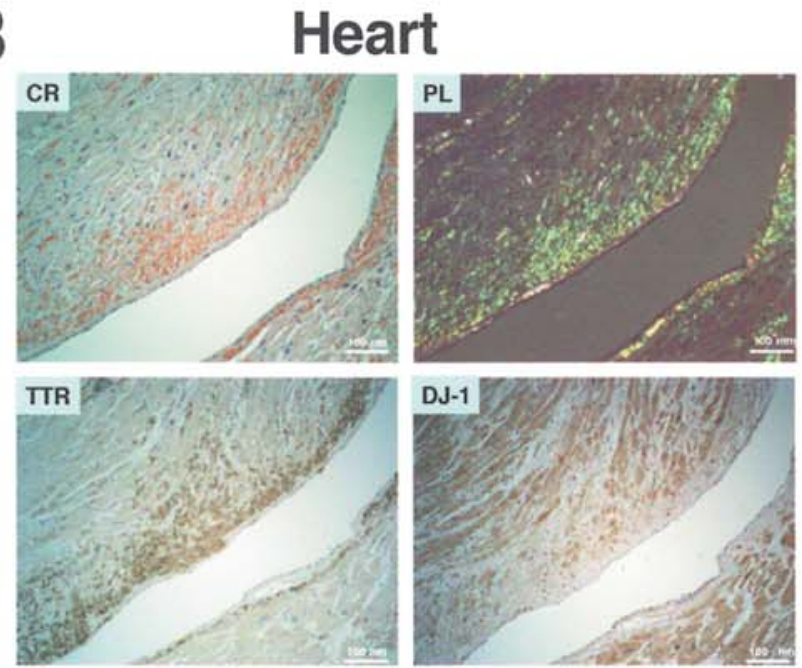

\section{Lumbar nerve}
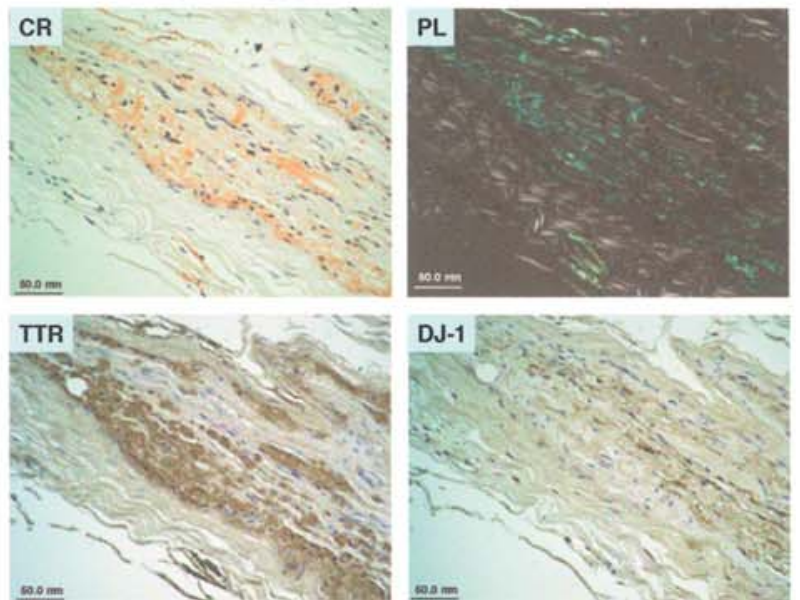
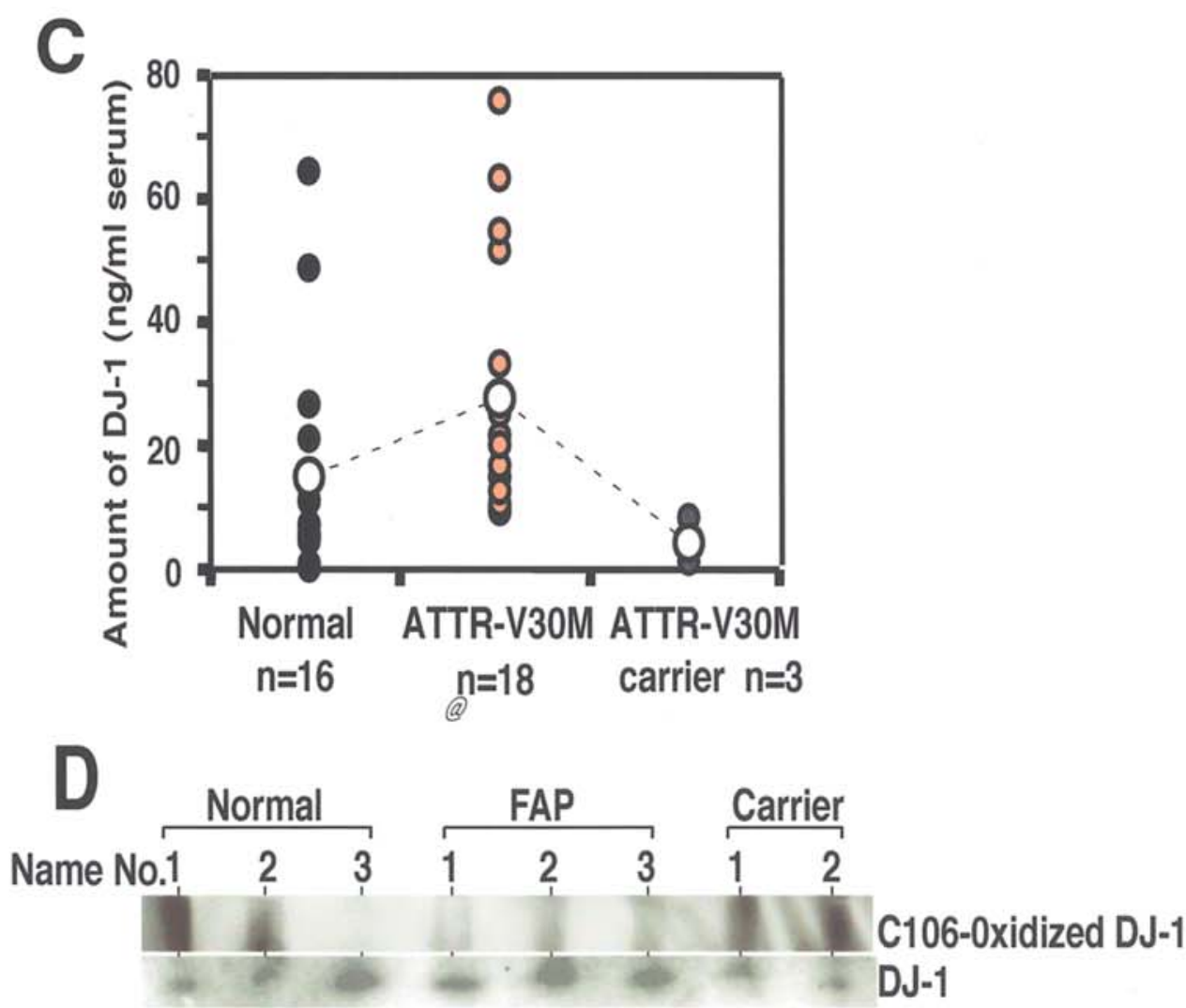

Figure 6. Immunohistochemical analysis of TTR and DJ-1 in human hearts and lumbar nerves of FAP patients (V30M) and secretion of an inactive form of DJ-1 into the serum of FAP patients. (A) Proteins from hearts of FAP patients (ATTR-V30M) were separated into 1\% Triton X-100-soluble (lane 1) and -insoluble (lane 2) fractions and analyzed by Western blotting with anti-DJ-1 and anti-TTR antibodies. (B) Sections were made from human hearts and lumbar nerves of FAP patients (V30M) stained with Congo red and examined under polarized light and were also reacted with anti-DJ-1 and anti-TTR antibodies followed by visualization with HRP-conjugated secondary antibodies. Magnification, x1000. CR, Congo red; PL, polarized light. (C) DJ-1 secreted into the serum of FAP patients (V30M) was measured by a sandwich ELISA. $\mathrm{p}=0.006$ compared to normal persons. (D) Proteins in the serum were first immunoprecipitated with the anti-DJ-1 antibody, and then precipitates were analyzed by Western blotting with anti-DJ-1 monoclonal (3E10) and anti-C106 oxidized DJ-1 antibodies 
(25), though controversial results have been reported $(28,29)$. An $\alpha$-helix ( $\alpha$-helix 9) at the C-terminal region of DJ-1 is thought to block the putative catalytic site of DJ-1 protease (24). The present study demonstrated that DJ-1 had a protease activity using a mixture of synthetic peptide and that DJ-1 lacking the $\alpha$-helix 9, DJ-1 (1-174), had stronger protease activity than full-sized DJ-1. Furthermore, C106S mutants of full-sized DJ-1 and DJ-1 (1-174) lost their protease activities, which is consistent with the idea that $\mathrm{C} 106$ is a catalytic site for DJ-1 protease $(24,25)$. We then identified TTR as a substrate for DJ-1 protease. The expression level of TTR in DJ-1-knockdown D2 cells was higher than that in parental NIH3T3 cells, and both wild-type and mutant TTR were degraded in cells transfected with full-sized DJ-1, suggesting that $\alpha$-helix 9 in DJ-1 was opened or cleaved by DJ-1binding protein(s) in cells to exert protease activity. Although such DJ-1-binding protein(s) is not identified at present, various chaperones that bind to DJ-1, including Hsp70, Chip and mitochondrial Hsp70, might be candidates $(38,39)$.

DJ-1 and TTR were co-secreted into the culture medium, in which monomer TTR was degraded and a secretion of DJ-1 was abrogated by oxidative stress, thereby increasing monomer TTR and resulting in the formation of amyloid fibrils. Since the culture medium was first centrifuged at 3,000 x g and its supernatant was used as the culture medium, in which actin was not detected by Western blotting, secreted DJ-1 into the culture medium was not derived from dead cells. It has been shown that a secreted monomer, but not tetramer, of TTR forms amyloid fibrils (3-6). DJ-1 was found to be co-secreted with a tetramer wild-type TTR into the culture medium under normal conditions. Under oxidative conditions, on the other hand, DJ-1 was not secreted and monomer, dimer and tetramer forms of both wild-type and V30M mutant TTR were accumulated in the medium, suggesting that DJ-1 prevents monomer formation of TTR.

The DJ-1 concentration in the serum of FAP patients was significantly higher than that in the serum of healthy persons and V30M-containing carriers. Secreted DJ-1 in the serum of FAP patients was found to be unoxidized DJ-1, which is an inactive form of DJ-1 as to its chaperone activity (27). Since it has not been shown that unoxidized DJ-1 is also the inactive form for DJ-1 protease, we are now examining this possibility. Furthermore, localization and solubility of TTR and DJ-1 in tissues of FAP patients were a mirror image; TTR and DJ-1 were located inside and outside amyloid fibrils, and TTR and DJ-1 were insoluble and soluble. These results suggest that oxidative stress acting on cells abrogates secretion of DJ-1 and that secreted DJ-1 degrades aggregated TTR to protect the onset of FAP. When secreted DJ-1 is inactivated by reduction, monomer TTR aggregates, resulting in the formation of amyloid fibrils.

A mirror image of localization of DJ-1 and $\alpha$-synuclein in Lewy bodies in tissues of Parkinson's disease patients has also been reported (40). Furthermore, it has been reported that DJ-1 was secreted into the cerebrospinal fluid of patients with stroke and that DJ-1 may be used as a plasma marker for the early diagnosis of stroke (41). These findings together with our present study suggest that in addition to Parkinson's disease, DJ-1 is related to oxidative stress-related neurodegenerative disorders.

\section{Acknowledgements}

We thank Yoko Misawa and Kiyomi Takaya for their technical assistance. This study was supported by grants-inaid from the Ministry of Education, Science, Culture, Sports and Technology of Japan and the Ministry of Health, Labor and Welfare of Japan.

\section{References}

1. Buxbaum JN and Tagoe CE: The genetics of the amyloidoses. Rev Med 51: 543-569, 2000.

2. Merlini G and Bellotti V: Molecular mechanisms of amyloidosis. N Engl J Med 349: 583-596, 2003.

3. Sacchettini JC and Kelly JW: Therapeutic strategies for human amyloid diseases. Nat Rev Drug Discov 1: 267-275, 2002.

4. Kelly JW: The alternative conformations of amyloidogenic proteins and their multi-step assembly pathways. Curr Opin Struct Biol 8: 101-106, 1998.

5. Damas AM and Saraiva MJ: TTR amyloidosis-structural features leading to protein aggregation and their implications on therapeutic strategies. J Struct Biol 130: 290-299, 2000.

6. Ando Y, Nakamura M and Araki S: Transthyretin-related familial amyloidotic polyneuropathy. Arch Neurol 62: 1057-1062, 2005.

7. Jacobson DR, Pastore RD, Yaghoubian R, Kane I, Gallo G, Buck FS and Buxbaum JN: Variant-sequence transthyretin (isoleucine 122) in late-onset cardiac amyloidosis in Black Americans. N Engl J Med 336: 466-473, 1997.

8. Nagakubo D, Taira T, Kitaura H, Ikeda M, Tamai K, Iguchi-Ariga SMM and Ariga H: DJ-1, a novel oncogene which transforms mouse NIH3T3 cells in cooperation with ras. Biochem Biophys Res Commun 231: 509-513, 1997.

9. Bonifati V, Rizzu P, van Baren MJ, et al: Mutations in the DJ-1 gene associated with autosomal recessive early-onset Parkinsonism. Science 299: 256-259, 2003.

10. Okada M, Matsumoto K, Niki T, Taira T, Iguchi-Ariga SMM and Ariga $\mathrm{H}$ : DJ-1, a target protein for an endocrine disrupter, participates in the fertilization in mice. Biol Pharm Bull 25: 853-856, 2002.

11. Klinefelter GR, Welch JE, Perreault SD, et al: Localization of the sperm protein SP22 and inhibition of fertility in vivo and in vitro. J Androl 23: 48-63, 2002.

12. Le Naour F, Misek DE, Krause MC, Deneux L, Giordano TJ, Scholl S and Hanash SM: Proteomics-based identification of RS/DJ-1 as a novel circulating tumor antigen in breast cancer. Clin Cancer Res 7: 3328-3335, 2001.

13. Miura K, Bowman ED, Simon R, et al: Laser capture microdissection and microarray expression analysis of lung adenocarcinoma reveals tobacco smoking- and prognosisrelated molecular profiles. Cancer Res 62: 3244-3250, 2002.

14. Takahashi K, Taira T, Niki T, Seino C, Iguchi-Ariga SMM and Ariga H: DJ-1 positively regulates the androgen receptor by impairing the binding of PIAS $\alpha$ to the receptor. J Biol Chem 276: 37556-37563, 2001.

15. Niki T, Takahashi-Niki K, Taira T, Iguchi-Ariga SMM and Ariga H: DJBP: A novel DJ-1-binding protein, negatively regulates the androgen receptor by recruiting histone deacetylase complex, and DJ-1 antagonizes this inhibition by abrogation of this complex. Mol Cancer Res 1: 247-261, 2003 .

16. Xu J, Zhong N, Wang H, et al: The Parkinson's diseaseassociated DJ-1 protein is a transcriptional co-activator that protects against neuronal apoptosis. Hum Mol Genet 14: 1231-1241, 2005.

17. Shinbo Y, Taira T, Niki T, Iguchi-Ariga SMM and Ariga H: DJ-1 restores p53 transcription activity inhibited by Topors/p53BP3. Int J Oncol 26: 641-648, 2005.

18. Nishinaga H, Takahashi-Niki K, Taira T, Andreadis A, Iguchi-Ariga SMM and Ariga H: Expression profiles of genes in DJ-1-knockdown and L166P DJ-1 mutant cells. Neurosci Lett 390: 54-59, 2005.

19. Ooe H, Taira T, Iguchi-Ariga SMM and Ariga $\mathrm{H}$ : Induction of reactive oxygen species by bisphenol $A$ and abrogation of bisphenol A-induced cell injury by DJ-1. Toxicol Sci 88: 114-126, 2005. 
20. Taira T, Saito Y, Niki T, Iguchi-Ariga SMM, Takahashi K and Ariga H: DJ-1 has a role in antioxidative stress to prevent cell death. EMBO Rep 5: 213-218, 2004.

21. Yokota T, Sugawara K, Ito K, Takahashi R, Ariga H and Mizusawa H: Down regulation of DJ-1 enhances cell death by oxidative stress, ER stress, and proteasome inhibition. Biochem Biophys Res Commun 312: 1342-1348, 2003.

22. Canet-Aviles RM, Wilson MA, Miller DW, et al: The Parkinson's disease protein DJ-1 is neuroprotective due to cysteine-sulfinic acid-driven mitochondrial localization. Proc Natl Acad Sci USA 101: 9103-9108, 2004.

23. Martinat C, Shendelman S, Jonason A, et al: Sensitivity to oxidative stress in DJ-1-deficient dopamine neurons: an ESderived cell model of primary Parkinsonism. PLoS Biol 2: e327, 2004.

24. Honbou K, Suzuki NN, Horiuchi M, Niki T, Taira T, Ariga H and Inagaki F: The crystal structure of DJ-1, a protein related to male fertility and Parkinson's disease. J Biol Chem 278: 31380-31384, 2003.

25. Olzmann JA, Brown K, Wilkinson KD, et al: Familial Parkinson's disease-associated L166P mutation disrupts DJ-1 protein folding and function. J Biol Chem 279: 8506-8515, 2004.

26. Shendelman S, Jonason A, Martinat C, Leete T and Abeliovich A: DJ-1 is a redox-dependent molecular chaperone that inhibits alpha-synuclein aggregate formation. PLoS Biol 2: e362, 2004.

27. Zhou W, Zhu M, Wilson MA, Petsko GA and Fink AL: The oxidation state of DJ-1 regulates its chaperone activity toward alpha-synuclein. J Mol Biol 356: 1036-1048, 2006.

28. Ito G, Ariga H, Nakagawa Y and Iwatsubo T: Roles of distinct cysteine residues in S-nitrosylation and dimerization of DJ-1. Biochem Biophys Res Commun 339: 667-672, 2006.

29. Moore DJ, Zhang L, Dawson TM and Dawson VL: A missense mutation (L166P) in DJ-1, linked to familial Parkinson's disease, confers reduced protein stability and impairs homooligomerization. J Neurochem 87: 1558-1567, 2003.

30. Shinbo Y, Niki T, Taira T, et al: Proper SUMO-1 conjugation is essential to DJ-1 to exert its full activities. Cell Death Diff 13: 96-108, 2006
31. Wilson MA, Collins JL, Hod Y, Ringe D and Petsko GA: e 1.1-A resolution crystal structure of DJ-1, the protein mutated in autosomal recessive early onset Parkinson's disease. Proc Natl Acad Sci USA 100: 9256-9261, 2003.

32. Kinumi T, Kimata J, Taira T, Ariga H and Niki E: Cysteine-106 of DJ-1 is the most sensitive cysteine residue to hydrogen peroxide mediated oxidation in vivo in human umbilical vein endothelial cells. Biochem Biophys Res Commun 317: 722-728, 2004.

33. Takahashi-Niki K, Niki T, Taira T, Iguchi-Ariga SMM and Ariga $\mathrm{H}$ : Reduced anti-oxidative stress activities of DJ-1 mutants found in Parkinson's disease patients. Biochem Biophys Res Commun 320: 389-397, 2004.

34. Ooe H, Iguchi-Ariga SMM and Ariga H: Establishment of specific antibodies that recognize C106-oxidized DJ-1. Neurosci Lett 404: 166-169, 2006.

35. Nakamura M, Yamashita T, Ueda M, et al: Neuroradiologic and clinicopathologic features of oculoleptomeningeal type amyloidosis. Neurology 65: 1051-1056, 2005.

36. Yamashita T, Ando Y, Katsuragi S, et al: Muscular amyloid angiopathy with amyloidgenic transthyretin Ser50Ile and Tyr114Cys. Muscle Nerve 31: 41-45, 2005.

37. Ando Y, Nyhlin N, Suhr O, et al: Oxidative stress is found in amyloid deposits in systemic amyloidosis. Biochem Biophys Res Commun 232: 497-502, 1997.

38. Li HM, Niki T, Taira T, Iguchi-Ariga SMM and Ariga H: Association of DJ-1 with chaperones and enhanced association and colocalization with mitochondrial Hsp70 by oxidative stress. Free Radic Res 39: 1091-1099, 2005.

39. Moore DJ, Zhang L, Troncoso J, et al: Association of DJ-1 and parkin mediated by pathogenic DJ-1 mutations and oxidative stress. Hum Mol Genet 14: 71-84, 2005.

40. Bandopadhyay R, Kingsbury AE, Cookson M, et al: The expression of DJ-1 (PARK7) in normal human CNS and idiopathic Parkinson's disease. Brain 127: 420-430, 2004.

41. Allard L, Burkhard PR, Lescuyer P, Burgess JA, Walter N, Hochstrasser DF and Sanchez JC: PARK7 and nucleotide diphosphate kinase A as plasma markers for the early diagnosis of stroke. Clin Chem 51: 2043-2051, 2005. 